\title{
XLVI. Improvement on the sliding-rule
}

\section{Silvanus Bevan Esq.}

To cite this article: Silvanus Bevan Esq. (1817) XLVI. Improvement on the sliding-rule, Philosophical Magazine Series 1, 49:227, 187-188, DOI: 10.1080/14786441708637877

To link to this article: http://dx.doi.org/10.1080/14786441708637877

曲 Published online: 27 Jul 2009.

Submit your article to this journal 준

Џ Article views: 2

Q View related articles $₫$ 


\section{$\left[\begin{array}{ll}187 & \end{array}\right]$}

\section{Improvement on the Sliding-Rule. By Silvanes Bevan, Esq.}

Most of the following description of a little invention of mine, which seems likely to extend the uses of the sliding-rnle, was prepared about nine months ago with a view to insertion in the Philosophical Magazine; but more important matters having then oceasioned it to be neglected, I now offer it for that purpose. I call it my iuvention, because it is new to me, and to all my scientific filends to whom I bave shown it; and because the advantages which it promises over the old construction would probahly have prevented it from lving dormant if it had previously occurred to others. And J think I am warranted in this conclusion by the circumstance, that but a very short time had elapsed after its first promulgation, when so niuch of it as appeared to be adapted to the purposes of the Board of Excise was introduced into general practice under its authority.

The anuexed drawing (Pl.III.fig.5) shows that, instead of having, like the coinmon sliding-rule, a fixed and a moveable line of numbers, each reaching from 1 to 10 , and repeated to a second 10 ; mine has one line reaching from 1 to 10 , and another reaching from about 3 to 10 , and thence onward to $3 \cdot 3$; or more exactly, from the square root of $10,3 \cdot 163$, to the repetition of the same number; one of these lines being inverterl, or counting from right to left, whilst the other is placed in the usual manner. By this construction, without any diminution of its uses (as I shall presently show), the slicling rule is reduced to one half its usual bulk, to the great increase of its portability and convenience; or, if its original length be retained, the size and accuracy of its divisions are doubled. But these are the least of its advantages: for while it performs the usual operations of multiplication, division, and proportion, with as much facility as the common sliding-rule, it also shows, on inspection, the square root and all the factors of a number given. For, bv the construction of the line of numbers, the distance between the first and second terms of a given proportion equals the distance between the third and fourth; and by the inversion of one of the scales it happens, that if the second and third terms are made to coincide, the first and fourth will coincide also. Hence it follows, that in any given position of the slide, the products of coincident numbers are equal thronghout; an $I$ if one of these numbers be unity, the correspondent number is the product of every contiguous pair, which are consequently its factors, and its root is hhown by their equality. For example: Let it be required to multiply 16 by 4:-place those two factors together, as in the figure; and opposite to 1 will be foumd the product 64 . Divide 64 by 2 :- 
place 1 opposite to 64 ; and against the divisor 2 will stand the quotient 32. Given 4,8 , and 8 , to find a fourth proportional :place 8 opposite to 8 ; against 4 is found 16 . To find the factors of $64:-$ bring 1 to that number ; in this position of the scale every factor will be found opposite to its reciprocal ; as 2 against 32,4 against 16,8 against 8 , which is consequently the square root of the given number. Or, if the factors of 640 be required, the same position of the slide shows that $2 \times 320,4 \times 160$, $5 \times 128,8 \times 80,10 \times 64,16 \times 40$, and $20 \times 32$, equally produce that number; whilst the juxtaposition of $25 \cdot 3$ in both lines shows that to be its root with as much accuracy as can be expected from so short a radius.

The scale reduced in length in the manner above described, but without the inversion of either of its lines, is competent to the solution of all questions of simple multiplication or division; and in this form it is prepared for the use of the officers of the Exeise by R. B. Bate, of the Poultry, the accuracy and neatness of whose workmanship I cannot avoid mentioning, though I am sensible they are too well known to derive any publicity from this notice of them.

Feb. 8, 1817.

Silvanus Bevan.

XLVII. SomeRemarks upon an urinary Calculus having a Cinder: as its Nucleus; with a Notice of other Calculi containing a small Quantity of Carlonate of Lime. The occurrence also of Brown Spar, noticed in the Trap Ruck near Newport in Gloucestershire.

To Mr. Tilloch.

$\mathrm{SiR}_{\mathrm{R},-} \mathrm{H}_{\mathrm{AVING}}$ seen in one of your late numbers an account of an urinary calculus chiefly composed of carbonate of lime, J have been induced to send you the following particulars of a calculus composed likewise of carbonate of lime, and further interesting from the substance forming its nucleus.

This substance is a common cinder, and it constitutes the greater part of the specimen. Although it is impossible to mistake its appearance, I may observe that sulph. acid when treated with a very small quantity of it very soon acquired a dark-brown colour. The cinder is surrounded but not intermixed with a layer of a vellowish-white colour, which dissolves in muriatic acid with a brisk effervescence, leaving behind a few tender flocculi. The solution being treated with subcarbonate of potash yielded carbonate of lime nearly to the amount of the original quantity employed; viz. two grains. To certify the presence of carbonic acid, I put a very small quantity of the calculus in a two-dram bottle, which immediately upon being filled with a di- 